\title{
The Study on Legal Control System of Atmospheric Pollution in China
}

\author{
Zhong Tianyao
}

(North China Electric Power University, Beijing, 102206)

Keywords: Atmospheric pollution; atmospheric pollution prevention; legal system

\begin{abstract}
After entering the industrial society, the industrial production activities of humans have increasingly serious degree on atmospheric destroy. PM2.5 is seriously exceeding. In order to protect survival environment of humans, restrict global temperature increase and prevent from reduction of air quality, China must enlarge the prevention strength of atmospheric pollution. In terms of prevention for atmospheric pollution, it is essential to fabricate relevant laws and regulations. Laws and regulations of atmospheric pollution prevention can provide essential basis for carrying out prevention and indicate some basic aspects. In the paper, the author will analyze causes for atmospheric pollution, point out some problems existed in prevention laws of atmospheric pollution in China, and offer some perfect advice.

Introduction: The atmospheric pollution in China has been increasingly serious, while highly developing social economy. At present, about $60 \%$ of people in China has been suffering from atmospheric pollution damage with varying degree. In Beijing, Shanghai, Guangzhou and Shenzhen, etc., PM2.5 content in the air is a lot and has already greatly exceeded international general standards, indicating that atmospheric pollution in China has already been very serious. Relevant legal system of prevention and measure system have no obvious effect. In order to improve atmospheric pollution prevention, it is necessary to perfect relevant laws and regulations.
\end{abstract}

\section{Causes for Atmospheric Pollution}

Atmospheric pollution is mainly caused by human production and life, such as fuel burning and automobile emissions. Before the industrial revolution, influences of human activities on natural environment were relatively small. The destroy degree on the environment didn't exceed self-repair strength of natural environment, resulting that natural environment could remain stable within in a long time. However, after entering into the industrial revolution, destroy degree of human activities on natural environment is greatly increased and gradually exceeded the self-repair strength of natural environment. All kinds of chemical industry production and resource exploitation resulted in destroying natural environment and exhausting resources. Atmospheric pollution is one of the most serious problems. The pollution sources of atmospheric pollution mainly include three types: First of all, it is the combustion of various industrial fuels. In the process of chemical industry production, combustion of various fuels is often required to provide energy required by industrial devices, such as thermal power generation, steel smelting, cement production and chemical synthesis, etc. If these fuels aren't burnt completely, they will generate some gaseous pollutants, such as sulfur dioxide and carbon monoxide, etc., causing atmospheric pollution and destroy, as well as tail gases discharged by various traffic means of transportation. In the modern society, people's living standard is greatly improved and the number of private cars is greatly increased. The tail gases exhausted by these cars 
include hydrocarbon, nitric oxide, carbon monoxide and sulfur dioxide, etc ${ }^{[1]}$. These gases not only will cause pollution and destroy to the atmosphere and also are inducing factors of acid rain, etc. At last, there are some life pollutants. For example, northern residents will fire coal for heating in winter, and it will generate some suspending particular matters, sulfur oxide and nitric oxide, which are discharged into the atmosphere to cause pollution.

\section{Existing Problems of Protective Laws for Atmospheric Pollution in China}

(1) Imperfect Total Quantity Control

After China started to implement the revised Atmospheric Pollution Prevention Law in January $1^{\text {st }}$ in this year, standards of atmospheric pollution prevention were expressly stipulated. Moreover, the overall atmospheric pollution prevention in China has been deployed and planned ${ }^{[2]}$, because Chinese laws and regulations of atmospheric pollution prevention have deficiency and they just aim at some critical pollution sources and pollution units. The total quantity control is insufficiently comprehensive. For some pollutants with small contents, there are no stipulated discharge and control standards.

(2) Problems in Implementation of Pollutant Permit System

The pollutant permit system refers to the system that the environmental protection department checks the units or individuals that discharge pollutants in the air and they can discharge pollutants after the environmental protection department approves it. Nevertheless, the regional pertinence of pollutant permit system is obvious. On the one hand, the jurisdictional limits are often kept in the regional ranges. On the other hand, atmospheric pollution is equipped with the diffusivity, thus it will impact surrounding atmospheric environment. This is out of consideration when China executes the pollutant permit system.

(3) Incomplete Environmental Standard System

The quality standards of atmospheric environment mainly include three aspects: air quality standards, pollutant discharge standards, and environmental monitoring standards ${ }^{[3]}$. Nowadays, quality standards in these three aspects are still imperfect. For example, air quality standards have no stipulations on content standards of PM2.5 in the air. Pollution discharge standards cover incomplete categories of pollutants. Devices and facilities depended by environmental monitoring standards are seriously insufficient.

\section{Perfect Suggestion on Laws and Regulations of Atmospheric Pollution Prevention}

(1) To Reinforce Total Quantity Control

In Atmospheric Pollution Prevention Law implemented in China, pollution discharge standards of atmospheric pollution are strictly stipulated. The systematic atmospheric pollution prevention is conducted within the whole country, including PM2.5 and various pollutants that may be changed into PM2.5. In addition, the coverage range of pollution sources and pollution units is greatly expanded. The total quantity control strength is greatly enhanced.

(2) To Execute the Pollutant Permit System

China should further execute and perfect the pollutant permit system. According to 
historical pollution discharge state, regional economic conditions and environmental conditions in various areas, discharge indicators should be distributed. Environmental protection department should grant the pollutant permit system cautiously and checks unit scale, industry, production level and hardware condition of facilities in strict accordance with legal steps. In addition, it is necessary to establish the third-party monitoring system out of the environmental protection department and enterprises, so that pollutant discharge will be supervised by the public. The public can be granted with the right of participation in environmental protection.

(3) To Establish the Complete Environmental Standard System

China should perfect the system of environmental standards, refer to international general environmental sanitary standards, quote or adjust numerical values directly or suitably. For example, in the Air Quality Standards issued by the WHO, contents of PM2.5 are lower than $25 \mu \mathrm{g} / \mathrm{m}^{3}$. This is the clause that is short in the air quality system in China. Furthermore, for some additional conditions of some environmental standards, the laws and regulations of atmospheric pollution prevention should be referred and can't be neglected.

Conclusions: Atmospheric pollution is one of the most serious environmental problems in modern society and has a close relation with human survival and development. In current days, the laws and regulations of atmospheric pollution prevention in China are shortage and have some defects. Chinese government should reinforce the control of total discharge pollutants, further implement the pollutant permit system, perfect environmental standard system in China, and provide the good natural environment for people's life.

\section{References:}

[1] Cai Wencan, Failure of Chinese Atmospheric Pollution Prevention System and Countermeasures-With the Analytical Framework of the North's Institution Change Theory[J] Journal of Huaqiao University(Philosophy and Social Science Version), 2014, 04: 115-124;

[2] Li Xianfeng, Background, Problems and Suggestion on Revising Atmospheric Pollution Prevention Law[J], Theory Monthly, 2015, 04: 102-106;

[3] Yu Junhong and Gao Guilin, Legal Reflection on Perfecting Atmospheric Pollution Prevention in Rural China[J], Environmental Protection, 2016, 05: 51-53

About the author: Zhong Tianyao(1998-), male, Nanchang, Jiangxi, Science of Law 